Carbon Dioxide from Fossil Fuel Power Plants in The U.S.", Brookhaven National Laboratory, BNL 35666 (1984)

\title{
A Proposal for Gas Storage on the Ocean Floor Using Gas Hydrates
}

Kazunari Ohgaki and Yoshiro Inoue

Dept. of Chem. Eng., Osaka Univ., Toyonaka 560

Key Words : Clathrate, Gas Hydrate, Carbon Diexide, Sea Water, Gas Storage

A method of gas storage on the ocean floor using double layers of gas hydrates and highly concentrated ionic solutions is proposed. The gas molecules diffusing from a storage house are repressed by the double layers. Not only $\mathrm{CO}_{2}$ but also gas mixtures such as $\mathrm{SO}_{\mathrm{x}}, \mathrm{NO}_{\mathrm{x}}$, and fluorocarbons can be stored in the compressed state by use of this method.

\section{レーザー光散乱法による有機相一水溶液系におけ る界面張力波の検出之界面濃度の推定 ${ }^{\dagger}$}

\author{
神吉達夫・浅野 強・芳川清和 \\ 姫路工業大学工学部 産業機械工学科 ${ }^{\dagger \dagger}$
}

\section{緒 言}

異相系流体界面では，配列した分子の熱運動によるゆ らぎと，乙れを抑制しようとする界面張力との相互作用 によって界面張力波が生じている. 流体力学によると、 界面張力波の波数, 振動数抢よび減衰摔は、界面張力、 界面粘性率抢よび界面弾性率などの界面の諸特性値よ関 数関係にある ${ }^{1,4,5)}$. このととに着目して, Löfgren らは レーザー光散乱法を用い, 有機相/水系における界面張 力の測定を試みている ${ }^{6)}$ 。しかし，界面活性物質などを 含む溶液系について界面張力波を検出し，界面濃度を推 定しようとした例はみられない，本研究では，有機相／ 水溶液系に対しレーザー光散乱法を適用して界面張力波 の検出を試み，界面張力および界面濃度の推定を行った。

† 1990年12月 7 日受理 ; 化学工学会徳島大会 (徳島, 1989年 7 月）抢よび同第23[可秋季大会（金沢，1990年10月）にて 発表

†† $\mathbf{7} 671-22$ 姫路市書写 2167

\section{1. 実 験}

\section{$1 \cdot 1$ 測定原理}

界面の流体力学によると, 界面張力波による变位 $y$ は 次式によって表現される ${ }^{1 !}$.

$y \propto \exp (-i \omega t) \cos k x$

ここに， $k$ は波数， $\omega\left(=\omega_{0}-i r\right)$ は複素振動数。 $\omega_{0}$ は 振動数、 $r$ は減衰率である。また, 界面張力 $\sigma$ は界面張 力波の特性值之次式で関係づけられる.

$$
\begin{aligned}
& \left\{\left(\rho_{1}+\rho_{2}\right) \omega^{2}-g \cdot\left(\rho_{2}-\rho_{1}\right) k-k^{3} \sigma\right\} \cdot\left\{\left(\eta_{1} k+\eta_{2} m_{2}\right)\right. \\
& \left.+\left(\eta_{2} k+\eta_{1} m_{1}\right)\right\}+4 i \omega k\left(\eta_{1} k+\eta_{2} m_{2}\right)\left(\eta_{2} k+\eta_{1} m_{1}\right) \\
& =0
\end{aligned}
$$

ただし、 $m_{i}=\left\{k^{2}-\left(i \omega \rho_{i} / \eta_{i}\right)\right\}^{1 / 2}\left(i=1,2 \operatorname{Re}\left[m_{i}\right]>0\right)$ 添 え字 1,2 はそれぞれ油相および水相を表す。 $\eta_{i}$ は粘性係 数、 $\rho_{i}$ は密度である。 $\eta_{i}$ および $\rho_{i}$ が既知であるとする 之， $\sigma$ はEq.(2)より推定される．今，吸着分子が界面で 単分子層を形成していると, Gibbsの式より界面張力 $\sigma$ は界面濃度 $\Gamma$ および溶質濃度 $C$ 上次式によって関係づけ られる。

$$
\Gamma=\Gamma^{\infty} \cdot\left[k_{a d} C /\left(1+k_{a d} C\right)\right]
$$




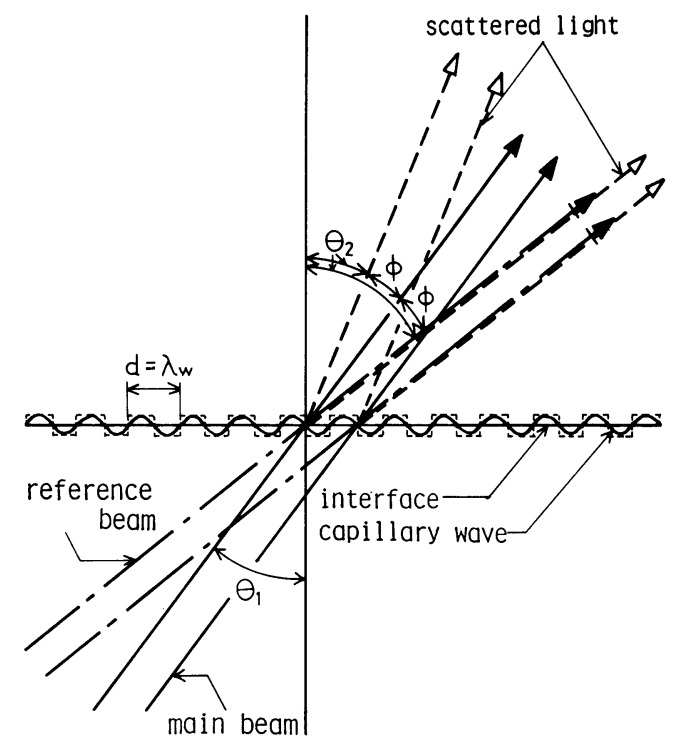

Fig. 1 Physical scheme of light beam scattering

$$
\sigma-\sigma_{0}=-\mathrm{RT} \Gamma^{\infty} \ln \left(1+k_{a d} C\right)
$$

ただし、 $\sigma_{0}$ は純粋な 2 相系での界面張力， $\Gamma^{\infty}$ は飽和界 面濃度, $k_{a d}$ は吸着平衡定数である.

Fig. 1 亿示すように界面にレーザー光を照射すると， 界面張力波は回折格子として作用するため、光は回折さ れ, 主光に対して対称の位置に微小な強度の散乱光を生 じる. 入射角を $\theta_{1}$ ，格子定数を $d$ とすると，界面張力波 によって散乱される相隣る光の光路差 $\Delta$ は、 $\Delta=d \sin$ $\theta_{2}-d \sin \theta_{1}=\lambda$ で表される. 界面張力波の波数 $k(=$ $\left.2 \pi / \lambda_{w}\right)$ は， $\theta_{2}=\theta_{1} \mp \phi, d=\lambda_{w}$ なることを考慮する と次式で与えられる.

$$
k=(2 \pi / \lambda) \cdot\left\{\cos \theta_{1} \sin \phi \pm 2 \sin \theta_{1} \cdot \sin ^{2}(\phi / 2)\right\}
$$

したがって，入射角 $\theta_{1}$ と $\phi$ が知れると、Eq.(5)より界面 張力 の波数べクトルを求めることができる。なお、一 般にめは微小であるので, $\sin \phi$ 值は界面と検出面ま での距離 $L$, 検出面における主光之第一回折光の間の 距離 $u$ から決定される. $\sin \phi \simeq u / L_{o}$

ところで, 主光は様々な波数の界面張力波によって散 乱され，しかもその強度は極めて微弱であるため, 特定 の $k$ 值の波による散乱光のみを直接検出するてとはでき ない. 今、比較的強い参照光を界面で主光と交差させる と, 参照光は特定の $k$ 值の散乱光とコヒーレントに重な りこれを変調増幅する (super heterodyne). 散乱光の電 界は，界面の変位を直接反映し，一般に， $E_{1}(t) \cos \Omega t$ $+E_{2}(t) \sin \Omega t$ なる形式で表される ${ }^{2)}$. 乙れに参照光の 電界 $E_{0} \cos \Omega t$ ( $E_{0}$ は電界振幅, $s$ は振動数) を重ねる之. 検出器面で出力される光電流 $I(t)$ は次式で与えられる.

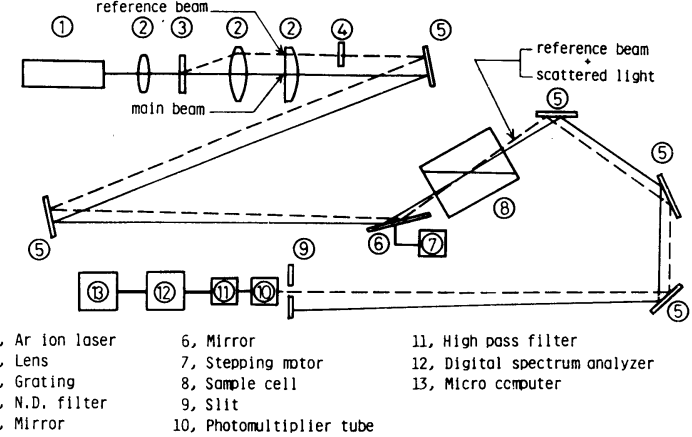

Fig. 2 Experimental apparatus, optical path system

$$
I_{0}+I(t) \propto\left\{E_{0}^{2}+2 E_{0} E_{1}(t)+E_{1}^{2}(t)+E_{2}^{2}(t)\right\} / 2
$$

余弦波 $E_{1}(t)$ は $E_{0}$ 倍に増幅され, 正弦波 $E_{2}(t)$ は検出さ れない（第 3，4項は無視小信号である）。

\section{$1 \cdot 2$ 装置および方法}

実験装置の概略を Fig. 2 亿示す. アルゴンイオンレー ザー（波長 $488 \mathrm{~nm}$, 出力 $150 \mathrm{~mW}$ ) からのビームは，透過 型回折格子 $(300 / \mathrm{mm})$ により主光およびこれと角度 $8.36^{\circ}$ をなす参照光に分けられ、レンズにより界面で交差する ように調節されている. また参照光はN.D.フィルターに より約 $1 / 50000$ に減光される。 サンプルセルは，一辺 80 $\mathrm{mm}$ の立方体状の石英製光学セルで，主光がセル光学面 に対し垂直に入射するよう設定されている．界面に入射 した主光は界面張力波の波数ベクトル，入射角打よび波 長によって決定される方向に散乱する．散乱光は参照光 と重なり，フォトマルの検出面に入射する. 主光および 迷光はスリットによって遮断される. 高周波透過フィル ターを通過した信号電流は，スペクトルアナライザに収 録解析され, 自己相関関数としてマイクロコンピュータ に記録される．本実験では，波数 $30000 ５ 0000$ の界面張 力波を検出すべく ${ }^{6)}$, 光学系により $\theta_{1}=60 \sim 70, \phi=0.4$ 〜 $0.6^{\circ}$ に設定した.

界面張力波の自己相関関数 $G(\tau)$ は指数減衰余弦関数 で表される。

$$
G(t)=A \cdot \exp (-r \tau) \cdot \cos \omega_{0} \tau+B
$$

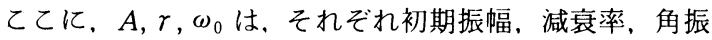
動数である. $B$ はノイズによって現れる定数項である. 本実験では, $n$-ヘプタン/水系, ベンゼン/水系および $n$-ヘプタン/ドデシル硫酸ナトリウム（以下SDS）水溶 液系を用いた。実験温度は $20^{\circ} \mathrm{C}$ である.

\section{2. 実験結果および考察}

$n$-ヘプタン/水系に対し, CRT画面に出力された界面 張力波の自己相関関数の一例を Fig. 3 亿示す. Eq. (7) で 示すような余弦減衰波を示している。乙こでは， $\omega_{0}, r$, $A, B$ の值を最小二乗法によって決定した。なお，本実験 
Table 1 Experimental values of wave parameters for various wave numbers

\begin{tabular}{|c|c|c|c|c|c|c|c|}
\hline & & \multicolumn{3}{|c|}{$n$-heptane/water } & \multicolumn{3}{|c|}{ benzene / water } \\
\hline$k$ & {$[1 / \mathrm{m}]$} & 31700 & 40180 & 49010 & 31200 & 47750 & 57800 \\
\hline$\omega_{0}$ & {$[\mathrm{~Hz}]$} & 4901 & 6963 & 9286 & 3787 & 7289 & 9302 \\
\hline$r$ & {$[1 / \mathrm{s}]$} & 2820 & 3910 & 3630 & 2910 & 3760 & 6610 \\
\hline$\sigma$ & {$[\mathrm{mN} / \mathrm{m}]$} & 50.78 & 50.40 & 49.58 & 35.30 & 34.60 & 34.30 \\
\hline$\sigma^{\prime}$ & {$[\mathrm{mN} / \mathrm{m}]$} & & 50.20 & & & 34.10 & \\
\hline
\end{tabular}

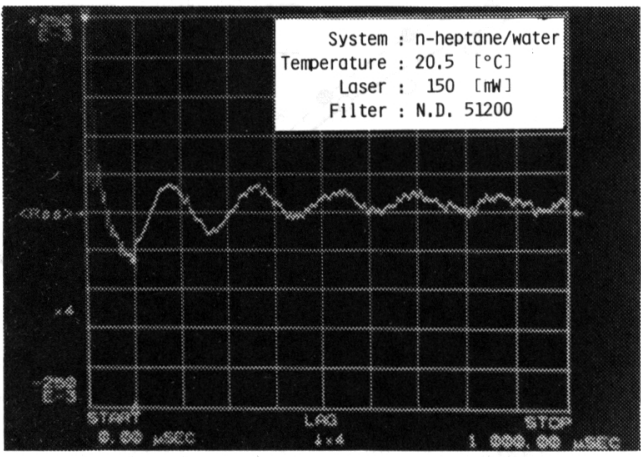

Fig. 3 Autocorrelation function of capillary wave on CRT display

では, $A=0.06 \sim 0.23, B=0.008 \sim 0.08$ 範囲であった.

Table 1 に, $n$-ヘプタン/水およびベンゼン/水系につ いて種々の波数 $\mathrm{k}$ に対して測定された自己相関関数の振 動数, 減衰率およびEq.(2) より推定された界面張力 $\sigma$ の 値を示す。 $\sigma$ の算出において、 $n$-ヘプタン, ベンゼンお よび水の粘性係数 クは，それぞれ $0.409,0.649,1.002$ $\left[\mathrm{mNs} / \mathrm{m}^{2}\right]$, 密度 $\rho$ はそれぞれ $684,880,1000\left[\mathrm{~kg} / \mathrm{m}^{3}\right]$ とした。また、本実験条件では、 $\operatorname{g}\left(\rho_{2}-\rho_{1}\right) / k^{2} \sigma \mid \simeq 10^{-5}$ と微少なため, Eq.(2)の重力項は無視した。表中の $\sigma^{\prime}$ は 文献值 (化学便覧) である. 本測定值はこれらの値よよ く一致している.

$n$-ヘプタン/SDS 水溶系について, 異なるSDS 濃度に 抢ける界面張力波の自己相関関数の測定例をFigs. 4 a c に示す. 濃度の差異による界面張力波の振動数および 減衰率の変化が認められる。 Fig. 5 に, SDS 濃度に対す る振動数と減衰率の関係を示している. 振動数は低濃度 域では濃度とと屯に減少し， $C \simeq 8 \times 10^{-3}\left[\mathrm{~mol} / \mathrm{dm}^{3}\right]$ で 不連続之なり，より高濃度でわずかに増加する傾向を示 している。一方, 減衰率は濃度とともに減少し、 $C \geqq 1$ $\times 10^{-3}\left[\mathrm{~mol} / \mathrm{dm}^{3}\right]$ 付近で増加し始め, $C=1 \times 10^{-3} \sim 8 \times$ $10^{-3}\left[\mathrm{~mol} / \mathrm{dm}^{3}\right]$ の領域で山状の曲線を示している：乙 の原因については現段階では明かでない，界面活性物質 を含む溶液系についても，界面粘弾性が小さいとき，Eq. (2) より $\omega_{0}$ との值を用いて界面張力を推定することが

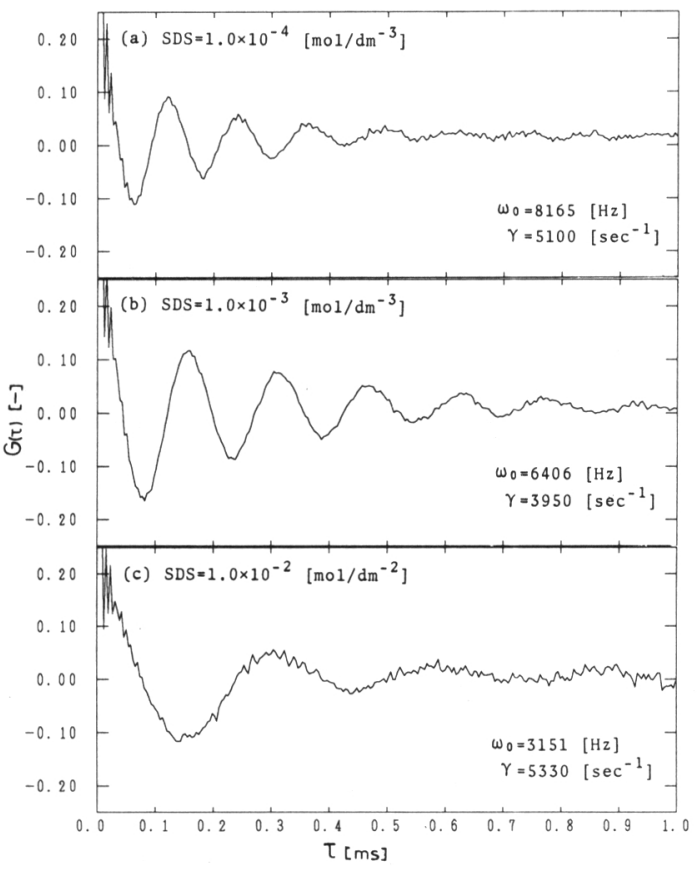

Fig. 4 Autocorrelation functions of capillary wave for several SDS concentrations, $n$-heptane/ SDS aqueous solution, $k=50,300 \mathrm{~m}^{-1}$

できる。このようにして推定された界面張力とSDS濃度 の関係をFig. 6 に示す。なお、この計算に必要な水溶液 の粘性係数についてはオストワルド法を用いて測定した ( Table 2). 図によると, 界面張力は濃度の増加ととも に減少し、 $C \geqq 8 \times 10^{-3}\left[\mathrm{~mol} / \mathrm{dm}^{3}\right]$ でやや増加している. 曲線の不連続点での濃度 $C \simeq 8 \times 10^{-3}\left[\mathrm{~mol} / \mathrm{dm}^{3}\right]$ は、臨 界ミセル濃度に対応する. 実線は $\Gamma^{\infty}=4.18 \times 10^{-6}[\mathrm{~mol} /$ $\left.\mathrm{dm}^{2}\right], \quad k_{a d}=4.72\left[\mathrm{~m}^{3} / \mathrm{mol}\right]$ としてEqs.(3),(4)より計算 された界面張力を示している。図の口印は，Kling らの 滴溶法による測定値 ${ }^{3 !}$, 破線は $\Gamma^{\infty}=5.47 \times 10^{-6}\left[\mathrm{~mol} / \mathrm{m}^{2}\right]$, $k_{a d}=1.80\left[\mathrm{~m}^{3} / \mathrm{mol}\right]$ としたときの界面張力の值である. 両者の傾向は全濃度域においてょく一致している。

結 言

レーザー光散乱法を溶液系に適用し, 本法が界面張力 
Table 2 Viscosity of SDS aqueous solution

\begin{tabular}{cccc}
$C\left[\mathrm{~mol} / \mathrm{dm}^{3}\right]$ & $\eta\left[\mathrm{mNs} / \mathrm{m}^{2}\right]$ & $C\left[\mathrm{~mol} / \mathrm{dm}^{3}\right]$ & $\eta\left[\mathrm{mNs} / \mathrm{m}^{2}\right]$ \\
$1 \times 10^{-4}$ & 1.039 & $7 \times 10^{-3}$ & 1.057 \\
$1 \times 10^{-3}$ & 1.039 & $1 \times 10^{-2}$ & 1.062 \\
$5 \times 10^{-3}$ & 1.042 & $2 \times 10^{-2}$ & 1.093 \\
\hline
\end{tabular}

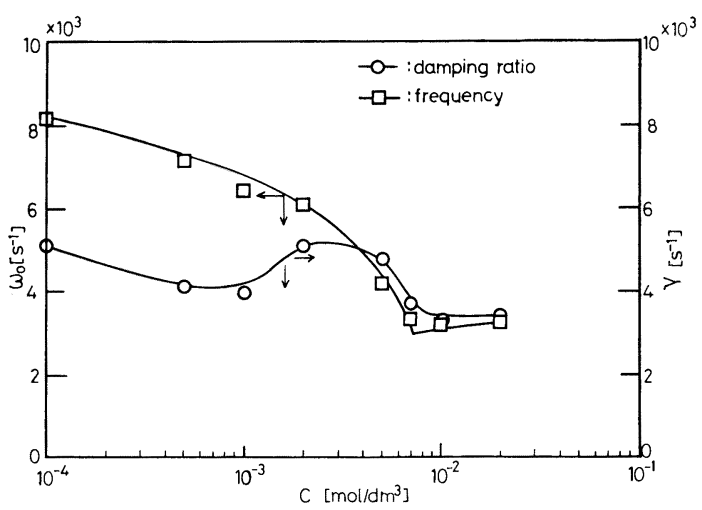

Fig. 5 Frequency and damping constant of capillary wave, $n$-heptane/SDS aqueous solution, $k=$ $50,300 \mathrm{~m}^{-1}$

および吸着質濃度を推定する上で有効な手段であること が示された。ここでは界面粘弾性の効果を無視したが, これについては今後検討したい。また抽出, 液膜なよ゙界 面反応系への拡張適用も試みたい.

[謝辞] 本研究は文部省科学研究費一般研究 C $(6255$ 0709）および兵漸県科学技術振興財団の補助を受けた。また, 実験計画抢よび装置の試作にあたり中林均氏 (ウシオ電機(㑣) のご協力を得た。記して謝意を表します。

\section{Nomenclature}

$$
\begin{aligned}
& A=\text { initial amplitude } \\
& B=\text { constant } \\
& C=\text { concentration of SDS } \\
& E_{0}=\text { electric field amplitude of reference } \\
& \quad \text { beam } \\
& E_{i}(t)=\text { electlic field amplitude of } \\
& \quad \text { scattering light } \\
& \begin{aligned}
G(\tau)= & \text { autocorreration function } \\
I(t)= & \text { photocurrent due to scattering light } \\
I_{0}= & \text { photocurrent due to reference beam } \\
k= & \text { wave vector of capillary wave } \\
k_{a d}= & \text { adsorption equilibrium constant } \\
R= & \text { gas constant } \\
T= & \text { absolute temperature } \\
t= & \text { time }
\end{aligned}
\end{aligned}
$$

$\left[\mathrm{mol} / \mathrm{dm}^{3}\right]$

$[\mathrm{volt} / \mathrm{m}]$

$[\mathrm{volt} / \mathrm{m}]$

$\left[\mathrm{m}^{3} / \mathrm{mol}\right]$

$[\mathrm{J} / \mathrm{K} \cdot \mathrm{mol}]$

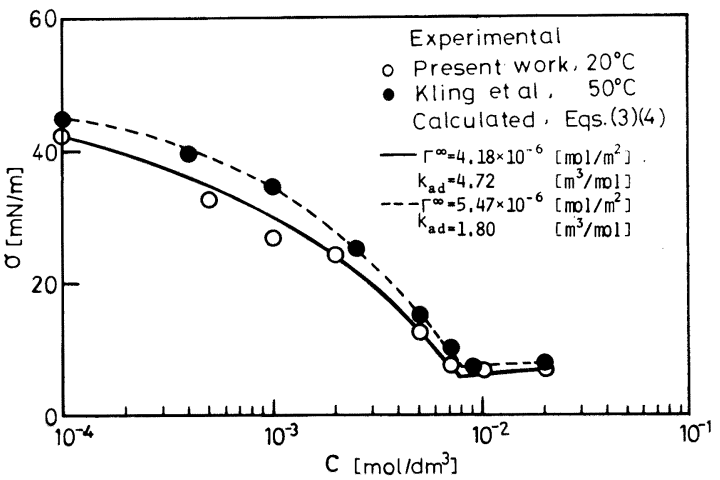

Fig. 6 Interfacial tension vs. SDS concentration, comparison with drop volume method data

$x=$ phase direction

$[\mathrm{m}]$

$y=$ displacement of interface

[m]

$\Gamma=$ surface excess

$\left[\mathrm{mol} / \mathrm{m}^{2}\right]$

$\Gamma^{\infty}=$ saturated surface excess

$\left[\mathrm{mol} / \mathrm{m}^{2}\right]$

$r=$ damping coefficient

$\left[\mathrm{s}^{-1}\right]$

$\eta_{i}=$ shear viscosity

$\left[\mathrm{N} \cdot \mathrm{s} / \mathrm{m}^{2}\right]$

$\theta_{1}=$ angle of incidence

[rad]

$\theta_{2}=$ angle of scattering light

[rad]

$\lambda=$ wave length of light

$\rho_{i}=$ density

$\left[\mathrm{kg} / \mathrm{m}^{3}\right]$

$\sigma=$ interfacial tension

$[\mathrm{N} \cdot \mathrm{m}]$

$\sigma_{0}=\sigma$ in pure liquid system

$[\mathrm{N} \cdot \mathrm{m}]$

$\tau=$ time lag

$\phi=$ angle between main beam and

[rad]

$\Omega=$ frequency of laser beam

$\omega_{0}=$ frequency of capillary wave

$[\mathrm{rad} / \mathrm{s}]$

\section{Literature cited}

1) Bellman, R. and R.H. Pennington: Quart. Appl. Math., 12, 151 (1954)

2) Hard, S., Y. Hamnerius and O.J. Nilsson : J. Appl. Phys., 47, 2433 (1976)

3) Kling, W. and H. Lamge: Proc. 2nd Int. Cong. 
Surface Activity, London, 1, 262 (1957)

4) Kramer, L. : J. Chem. Phys., 55, 2097 (1971)

5) Lamb, H.: “Hydrodynamics”, 6th ed., Cambridge
Univ. Press., p. 625 (1932)

6) Löfgren, H., R.D. Neuman, L.E. Scriven and H.T.

Davis: J. Colloid \& Interface Sci., 98, 175 (1983)

\title{
Detection of Capillary Wave in Organic/Aqueous Solution System from Laser-Light Scattering Me- thod and Estimation of Interfacial Concentration
}

\author{
Tatsuo Kanki, Tsuyoshi Asano and Kiyokazu Yoshikawa
}

Dept. of Chem. Eng., Himeji Institute of Technology, Himeji 671-22

\begin{abstract}
Key Words : Interfacial Tension, Surface Excess, Capillary Wave, Laser-Light Scattering

Capillary waves in $n$-heptane/sodium dodecyl sulfate aqueous solution system were detected by the laser-light scattering method to measure the interfacial tensions at various solute concentrations. The present measurements were shown to be consistent when compared with existing experimental results by the drop volume method. The interfacial concentrations of adsorbed species were estimated by the LangmuirGibbs equation. The laser-light scattering method was proved to be effectve for measuring in situ the interfacial tension and the interfacial concentration.
\end{abstract}

\section{晶析器内における破損によるカリミョウバン結晶の重量変化 ${ }^{\dagger}$}

\section{清水健司・細越広樹・久保田徳昭}

\section{岩手大学工学部 応用化学科 ${ }^{\dagger \dagger}$}

\section{緒 言}

晶析器内で結晶は、絶えず、器壁, 擋拌羽根および結 晶同士と衝突を繰り返し、その一部が損傷する破損、あ るいは原形をとどめないまでに壊れる破壊状態にあると 考えられるが, 結晶の破損, 破壊現象 ${ }^{2-6)}$ については従 来の報告ではあまり取り、上げられてはいない。しかし， 結鼠の破損, 破壊現象は, 製品結晶の粒度分布に著しく 影響を及ぼす1,2,7)ので, その現象を検討することは工業 的にも，工学的にあ重要であると考えられる。

そこで、本報告では、先ず, 问分晶析器内の結晶の形 態を観察し、結晶の破損, 破壊の確認を行い,さらに、 晶析器内の擋拌溶液中に結晶をつるし, 擋拌羽根と衝突 させた場合と結晶を懸濁させた場合の結晶重量を测定し,

\footnotetext{
† 1991年1月9日受理; World congress III of Chemical Engineering (東京, 1986年 9 月) にて発表 †† 020 盛岡市上田 $4-3-5$
}

結晶重量変化について実験的に調べた.

\section{1. 実験装置および方法}

晶析器はアクリル樹脂製で, 直径 $61 \mathrm{~mm}$, 高さ $110 \mathrm{~mm}$, 内側に幅 $6.5 \mathrm{~mm}$, 高さ $93 \mathrm{~mm}$ の 4 枚の邪魔板が取りつけ てある. 擋拌羽根としては, タービン型 6 枚羽根を用い, 槽底より $12.6 \mathrm{~mm}$ のところに取りつけた。

孔径 20〜30 $\mu \mathrm{m}$ のガラスフィルターを用い沪過した飽 和温度 $T_{s}=308.15 \mathrm{~K}$ のカリミョウバン水溶液を, 晶析器 に約 $200 \mathrm{~m} l$ 採った. 擋拌しながら溶液温度を所定の結晶 化温度 $T_{N}$ にした。 そして, 次の 2 通りの方法で結晶の破 損抢よび破砕による結晶重量変化を調べた。

\section{1 擋拌溶液中につるした結晶の重量変化の測定}

Fig. 1 (a)に示すように, 晶析器中に重量 60〜90mg の 結晶をつり糸でつるした。擋拌羽根に衝突しない結晶 (1) と衝突する結晶 (2)の 2 種類を準備した。撹拌羽根 を所定の速度で回転させ、溶液を擋拌するとともに、つ 